\title{
The Unpredictable Critical Threshold in COVID-19 Pandemic and Climate Change
}

\author{
Petre Roman \\ Department of Hydraulics, Hydraulic Machinery and Environmental Engineering, Faculty of Energy Engineering, Politehnica University of \\ Bucharest, Bucharest, Romania \\ Email address: \\ proman@clubmadrid.org \\ To cite this article: \\ Petre Roman. The Unpredictable Critical Threshold in COVID-19 Pandemic and Climate Change. International Journal of Environmental \\ Monitoring and Analysis. Vol. 9, No. 4, 2021, pp. 104-108. doi: 10.11648/j.ijema.20210904.12
}

Received: June 7, 2021; Accepted: July 19, 2021; Published: July 29, 2021

\begin{abstract}
In the real world we are confronted with situations where tiny variations in initial conditions can have major influence on unfolding events within the natural systems. We call it "sensitive dependence on initial conditions". When predictions are virtually impossible, we have to be capable of detecting in advance the patterns and qualitative features of the natural systems behaviour. But, the moment of truth, unpredictable, can appear in the form of a drastic change, when a critical threshold (tipping point) is reached. It is by no means clear that the dioxide gas accumulation and the greenhouse effect will follow, as of now, a gradually increasing path. More probable we will face, at some not distant point in the near future, a moment when a critical threshold is reached and then, a dramatic and more dangerous change happens. Another example clearly indicates the same tipping unpredictability: a major Antarctic glacier is at risk of disintegrating irreversibly if it passes a key tipping point. The COVID-19 pandemic is the most recent case in point. Within this framework of ideas and concepts a different kind of question is needed: Does humanity have property rights and in the meantime the subject of the present day is global coordination and even more: cultural evolution. Worried about the effects of climate change, we need to remember that every single action within a global system depends for its success on cooperative behaviour.
\end{abstract}

Keywords: Unpredictability, Critical Threshold, Climate Change, COVID-19

\section{Introduction}

The present paper is focused on the unpredictability of natural phenomena and the occurrence of critical thresholds (tipping points) in the dynamics of natural systems, i.e. dynamic (nonlinear) systems which are sensitive to the change of initial conditions. As a result of such sensitivity they develop chaotic behaviour.

Unpredictability, namely the lack of absolutely complete information, present in the very essence of nature, assumes limitations, as well, manifested in humans' projects and actions, but not in their thinking. Limits induce uncertainty. Solving uncertainty, a mandatory step in decision-making, needs a vast and complex image of thinking.

However, science is not about certainty. All we have are only provisional pieces of truth. Consequently, one should get accustomed to uncertainty and unpredictability.

As a matter of fact, science advances, always under uncertainty, towards more profound knowledge, yet without fully eliminating uncertainty. Briefly, science appears as the final sum of a large number, of a multitude of concepts and fundamental laws compatible with unpredictability.

Once confronted with uncertainty, thinking does not fly freely anymore, but it makes efforts to escape "astonishment" and to develop a strategy. This is the expression of lucidity and of the need of certainty.

More specifically, the accidental side of things appears to be unpredictability itself. Further on, uncertainty appears from unpredictability, once the latter occurs in the heart of nature, while uncertainty exists through the feeling of people, also perceived at society or community level.

Our destiny is manifesting in the struggle with hostile uncertainty, a struggle in which the solution does exist; however, this lies by no means in ignorance. "I will not permit hazard to judge me", stated Seneca; "luck involves no moral judgement". The master of the unknown is the poet of uncertainty.

Sensitive dependence on initial conditions serves not to 
destroy but to create. Chaos, for instance, doesn't respond to a particular line of a scientific discipline; chaos seems to be everywhere.

Deterministic systems could generate randomness. There is a limit on how much initial information can be gathered. Intriguingly, the chaotic behaviour of simple dynamic systems act as a creative process.

A natural system displays an average behaviour for a long period of time and then, for no apparent reason it shifts into a very different behaviour. It is a new average but it could be chaotic.

A well-defined scientific discipline aims to the resolution of well-defined problems. The nonlinear nature of natural systems (or economic, biological, chemical or even social) makes the task of coping with unpredictable events much more complex. Assembling a lot of information is the response to the sensitivity to initial conditions and it has to be an interdisciplinary effort.

The purpose of my work in the last two years (I wrote a book "Unpredictability\&Decision", published this year, 2021, in Romanian) is to show that the impact of unpredictability on decisional thinking could be, or even should be, analyzed from a variety of scientific perspectives: physics of the natural environment, logic of mathematics, logic of truth, quantum mechanics, economics, neurosciences, psychology and philosophy. Although such a diverse interdisciplinarity is difficult to grasp, not to mention the intent to wield several courses of scientific thinking into the process of economic decision-making, it is necessary to remember that under conditions of uncertainty and disorder we do not have models of quantitative prediction of the outcomes; we are, then, strongly interested in the patterns and qualitative features of the dynamics of the situations we are confronted with.

\section{Unpredictability and Order}

In physics, including that of the atmosphere or oceans, the random events may arise from the deeply complex dynamics. Henri Poincaré [1] left us a famous phrase: "Chance is only the measure of our ignorance", because, he said, "Fortuitous phenomena are by definition those whose laws we do not know". The essential question which derives from this definition is how the unpredictable events can be harnessed for the applications with the greatest impact on the real world. In the real world we are confronted with situations where tiny variations in initial conditions can have major influence on unfolding events within the natural systems. We call it "sensitive dependence on initial conditions". It was demonstrated by Edward Lorenz in 1963. [2] His conclusion, based on a computer simulation of the dynamics of the weather, was that long term weather prediction is impossible. Before him, in the late $19^{\text {th }}$ century, the Russian mathematician Aleksandr Lyapunov, invented the exponential numbers which describe the sensitivity of a system to its starting point. If a situation can be accurately predicted, it has a Lyapunov exponent of 0 . Above that threshold of zero lies unpredictability. The weather is a case in point.

The well-known cases are those of disruptive phenomena like storms, tornadoes, hurricanes, tsunami, heat waves, torrential rains and even the outbreak of virus epidemics like the Covid-19 these days.

"Predictability requires perfect knowledge of the Universe and exact laws of nature" says James Gleick [3]. The causes of random events are physically determined but so numerous and complex that they (the events) are unpredictable. "Instead of predictability, there is chaos". It doesn't mean that there is no order whatsoever in the natural system; there is interaction between order and randomness [see $4 \& 5$ ], not a straightforward one though. We should add what Kurt Gödel proved in 1931, that there must be truths, that is, statements that can never be proved. [6]

Science is not about certainty. Human knowledge itself is not certain. We can have only provisional truths. Therefore, we need to reach an accommodation with uncertainty and unpredictability. The words of Bertrand Russell need to be remembered: "Uncertainty in the presence of vivid hopes is painful, but must be endured...to teach how to live without certainty and yet without being paralysed by hesitation, is perhaps the chief thing" [7].

It means that uncertainty and unpredictability should not be defined in terms of the lack of something positive or better. Thinking does shine when it works in the area that "lies between too much certainty and too much doubt". [8]

The chaos theory came some years ago to rescue our natural propensity to predict behaviour of the natural systems. While we cannot attach precise values of their variables at a particular time, we can predict qualitative features of the system's behaviour. The shift from quantity and formulas to quality and pattern is in the meantime a shift to an essential way of thinking with practical consequences to the present human activity.

While humans are able to change the natural conditions and in doing so they have a strong impact on climate - it would be impossible to determine what climate would have done otherwise. The events cannot be predicted under the sensitive dependence on initial conditions; nevertheless, they can be explained. This became the conventional wisdom of business as well as political leaders. There lies probably the exponential growth of public relations.

Policies meant to mitigate the consequences of climate change should be tools to make possible changes in the society, i.e., to set the foundation of global decisions which aim at sustainable development conditions to prevail.

When predictions are virtually impossible, we have to be capable of detecting in advance the patterns and qualitative features of the natural systems behaviour. And such attempts are not easy. Benoit Mandelbrot indicated, in 1967, that for any problem we try to solve using the methods of building models of physics "we noticed everyday more that by adapting these methods to a new context, we ended up with results of extremely different form" [9]. For instance, all the predictions of the global economic and financial behaviour failed to signal the dramatic 2008 crisis. 


\section{The Critical Threshold in the Natural Phenomena}

In January this year (2020), the Davos Economic Forum organizer, Klaus Schwab, told the press: "We do not want to reach the critical tipping point of the irreversibility of climate change." This statement, which seems to me to be at the opposite of the "Davos spirit" which prevailed in many previous years, implies that we know when the tipping point might occur. Well, we don't. It's unpredictable.

On the same line of thought, President Trump said that "fear and doubt are not a good thought process". I think the doubt itself, regarding the geological and anthropogenic evolution of the Earth, should be an obligatory element of the thought process. Our faith in the strengths of facts is the foundation of our rationality, guiding the progress of civilization.

Climate optimists believe that nature's resilience is (almost) unbreakable and, as a consequence, the damages inflicted to the natural environment by human activities are very limited. Their optimism is based on their impression that the damages are gradual and very often are also invisible. But, the moment of truth, unpredictable, can appear in the form of a drastic change, when a critical threshold (tipping point in the American terminology) is reached.

From my own experience as a scientist in the field of hydrology and environmental quality, I can bring a specific example [10].

In 1975, an ample yearly program of sampling and hydrodynamic measurements was initiated in order to determine the quality of Danube water all along the $1075 \mathrm{~km}$ of the Romanian sector, from the discharge of the Nera River into the Danube, at the frontier with Serbia, and downstream up until the discharge of the Danube into the Black Sea. I led the hydrological research, and together with my colleagues, chemists and biologists, we took samples of water and simultaneously measured the speed and location of dozens of points of the dozens of sections selected along the $1075 \mathrm{~km}$ of the Danube. To our great surprise, we found that in $76 \%$ of the samples, the water quality was not just good; the water was drinkable. We could see people on the shore taking water from the Danube and drinking it. We were amazed, but they knew better. Ten years later, in 1985, on the order of the then President of the National Council for Science and Technology, Elena Ceaușescu, the dictator's wife, the whole program of research was cancelled. But in that year, we found that from $76 \%$ of drinkable water, the quality dramatically went down to $33 \%$. What happened in those ten years?

The most probable explanation would be that a critical threshold was reached, beyond which the low grading of the water quality went from gradual to drastic. The Danube has resisted "heroically" the assaults of the massive pollution inflicted by the big European cities (Vienna, Bratislava, Budapest, Belgrade) until its capacity of self-purification was doomed.

By transposition - acceptable (at least) on scientific grounds -the situation we registered then in the Danube River, one of the largest natural bodies on the planet, we can imagine the same type of dynamics of the present climate change. It is by no means clear that the dioxide gas accumulation and the greenhouse effect will follow, as of now, a gradually increasing path. More probable we will face, at some not distant point in the near future, a moment when a critical threshold (tipping point) is reached and then, a dramatic and more dangerous change happens. Another example clearly indicating the same tipping point feature was recently published in New Scientist [11], presenting the conclusions of scientific studies on the unpredictability of the melting of crucial glaciers. A major Antarctic glacier is at risk of disintegrating irreversibly if it passes a key tipping point. A domestic glacier retreat could let water get under the ice and thus collapse the entire ice sheet, leading to more than 3 meters of sea level rise, over a long period of time. We may be closer than we thought to Earth's dangerous tipping points. "It's highly likely that things might happen over a quicker period of time" says the study.

\section{Does Humanity Have Property Rights}

A recent result [12] of the investigation on the ice core records from the Himalayas aimed at understanding the onset and timing of the human impact of the atmosphere of the "roof of the world". In 1997, at the altitude of 8013 meters, the research team extracted three ice core samples measuring 150 meters depth. The successive layers of snow revealed the information from the past, as if they were tree rings; from the year 1499 to the present day ( $\sim 500$ years). Until 1780, the composition of the samples, determined with the latest techniques of investigation, showed only traces of metals of natural origin.

The results from 1780 onward suggest a strong contamination with toxic metals (augmented factors of 2 to 6 ) which was the consequence of the combustion of coal, likely from the Western Europe during the first Industrial Revolution in the $19^{\text {th }}$ century.

In the last 50 years the samples indicate more specifically traces of lead which obviously originates in the combustion of vehicle's engines.

In the meantime, the study detected particles emitted by the massive deforestation of the $19^{\text {th }}$ century, made not by logging but by burning the forests.

Western Europe lost 19 million hectares of forest, Russia another 33 million, and Romania nearly two million.

On average, in a European country today, the emission of $\mathrm{CO}_{2}$ per year and per person is about 14 tonnes, while a tree absorbs on average 22 kilograms per year. The balance is achieved if every person would plant approximately 680 trees per year. It certainly exceeds the real possibility of using this method to mitigate the carbon imprint. But by the development of an ample reforestation program (in Romania, for instance, there are more than 1 million hectares of degraded land) we could probably achieve an essential result: delaying significantly the occurrence of the critical threshold 
in the climate change.

Today, under the huge stress imposed by the COVID-19 pandemic, it became clear, once more, that the exit strategy should be a global effort since no country has a monopoly on science. In this context I want to refer briefly to the ability of scientific expertise to guide governmental policies. It is important to understand what are the real limits of treating the huge array of data which presumably should be correlated in order to offer a valuable response to the many questions underpinning the strategy elaboration. Unweaving the true connection between cause and effect is crucial. The problem is to correctly distinguish correlation from causation. A great deal of scientific practice is based on using statistical tools. Data and correlation are essential to indicate which method, among several different ones, lead to good results. But it doesn't mean that we know why or how to improve the methods. As the scientists say, we need to have a causal understanding. Science without causality doesn't make sense. As a matter of fact, intervening on the cause will change the effect, but not vice versa. We are always seeking to improve decision-making and that necessarily leads to understanding the cause-effect sequence. So, every leader in the world should ask: if I were to do this, how would the world change, not just my country and my people. The COVID-19 pandemic is the most recent case in point while better understanding climate change is increasingly important for the future of humanity. The global science effort today is to get a causal picture of biosphere and atmosphere interactions. These interactions have potentially dramatic consequences for our plans to tackle the global health problems and climate change effects. Urgency demands patience.

In the functioning of democracy there is rational ignorance. Voters do not need to know all the aspects of political, economic and social life to vote. They do have a clear idea of their own expectations. In the functioning of politics today we can observe political decisions which often indicate irrational ignorance, in the sense that political leaders do not want to know more because- they believe - it is useless. And they are wrong; at least because they ignore that we live in a world where both the expectations and the degree of confidence of the people, in many areas of the world, are situated at very low levels compared to not-so-distant times in the past. The cumulative interaction of the state of confidence with people's expectations at any moment can transform small disorders or disturbances of the "rules of the game" into major events with a tendency to break the existing systems. We can see already that the economy and the political systems are increasingly under the influence of climate change but it seems they do not seem to master strong enough stabilizing forces.

Let's use property rights as an example. To the economists, property rights mean something similar to the "rules of the game". "Property rights are rights to control the way in which particular resources will be used and to assign the resulting costs and benefits" and "Property rights create expectations. Expectations guide actions." [13] And I think that in our present world there is a demand for new definitions of property rights.

Adam Smith was probably the first and certainly the most important economist to consider the fact that ethics play an important role in economics. He expressed it by the fact that supply curves and demand curves depend on convictions and commitments that are fundamentally ethical in nature.

In another kind of approach, Nicholas Georgescu-Roegen stresses that [14, 15], "the true economic process is not a material flow of waste, but an immaterial flux: the enjoyment of life" and that: "the complete data of any economic problem must also include cultural propensities (of the people)"; and also "if we deny the people's capacity for empathy, then our exercise doesn't have any meaning". (A detailed economic and mathematical analysis of the same is presented in [16]).

Whenever we attempt to resolve conflicting claims, we try to avoid unexpected decisions or outcomes. And the decisions we take within an economic system depend crucially on the property rights which were established and are accepted by the society. Let's remember that property rights create expectations which, on one hand, are very important in shaping economic decisions but, on the other hand, are confronted with the uncertainty of decision making and unpredictable events.

Within this framework of ideas and concepts a different kind of question is needed: Does humanity have property rights?

It is absolutely clear that the market forces cannot temper the perturbations and negative effects in the dynamics of climate; on the contrary, as a rule, they amplify them. Who then will take care of the property rights of humanity on the path of harmonious conviviality with the planet?

The subject of the present day is global coordination and even more: cultural evolution. Worried about the effects of climate change, we need to remember that every single action within a global system depends for its success on cooperative behaviour. There are still dramatic gaps between the reality of unpredictable climate dynamics and the expectations and state of confidence of the people. Governments should take steps to close the gaps.

\section{Conclusion}

When you can't say what a system is going to do next you are confronting a situation of unpredictability which just generates uncertainty and disorder.

A system normally functioning represents the routine, an ordered and hierarchized assembly, settled for its scheduled operation. Uncertainty results from changes in the context or in the data usually employed. This means a new state-of-theart, created by a change produced beyond our reach. Modification of the normal condition is imposed by uncertainty, which forces the decision: either changing in the system, or changing of the system itself. The decisional transformation of the system, not only for the sake of adaptation but, possibly, for qualitative improvement, is either very important, if it means transformation in the 
system, or decisive, if it transforms the system.

A qualitatively new system, transformed from the old one, demonstrates not only what the old one used to demonstrate, but also its own stability. An absolutely new system needs a different consistency.

Transformation is transitional for assuring the system's stability and competitiveness. The change produced by a new uncertainty comes from something having occurred in the past, and yet it is a novelty. Instead, the change induced by decision becomes the - partial or total - future.

Thinking is a free game of the mind, which operates with ideas, without the obligation of proving something. By their very nature, human beings are manifested in a daily attitude which includes beliefs, judgements, opinions and theories about the world's reality and its full significance (as complete as possible, as a function of the available data). A phenomenological attitude involves distancing from this "natural" posture, a categorical refusal of illusions and of "bright" perspectives, alongwith assuming the concern for providing proofs and for rigour, for a permanent need of observing and accepting stratification, limpidity and concreteness, all these accompanied by the feeling that all we have at hand is a never-failing source of information. In this way, one will never be confined by either interpretation patterns, various prejudices or language. We know that logic operates with the language, and also that both philosophers and mathematicians felt an absolute need of fully and definitely formalizing the expression of thinking into language.

People have a natural propensity to want and to expect to live in an intelligible, comprehensible world. And yet, which would be the reason for which, or in what manner could one plainly declare that "I know"?

Indeed, we permanently and eternally harbour in us both the strive for an intrinsic cohesion of the world, and the compulsive limits of our knowledge.

\section{References}

[1] Henri Poincaré, "Science et Méthode", chap. 4, Le Hasard", Editions Flammarion, 1908, page. 68.

[2] Edward Lorenz, "Deterministic nonperiodic flow", Journal of Atmospheric Sciences, 1963, pag. 131-141.
[3] James Gleick, "The Unpredictable Nature of Dynamic Systems", essay in Gakushu.org, $18^{\text {th }}$ May 2011.

[4] Petre Roman, "Aération naturelle des écoulements à surface libre", PhD thesis, Paul Sabatier University of Toulouse, France, 18th of March 1974, introduction and page 96.

[5] Paul Manneville and co-authors, "Le Chaos"- théorie et expérience, Collection du Commissariat à L'Energie Atomique, Editions Eyrolles, 1988, pp. 83, 89-90, 117, 129, 285-287.

[6] Kurt Gödel, "On Formally Undecidable Propositions of Principia Mathematica and Related Systems I", Collected Works, Univ. Press, Oxford, 1986, pag. 145.

[7] Bertrand Russell, "Logic and Knowledge: Essays", Routledge, London, 1956, pag. 339.

[8] David Malone, "Can we learn to love uncertainty?" New Scientist, $4^{\text {th }}$ of August 2017, pag. 46.

[9] Benoit Mandelbrot, "Sur l'épistémologie du hasard dans les sciences sociales", in vol." Logique et connaissance scientifique, Editions Gallimard, 1967, p. 1112.

[10] "The Study of the Danube Water Quality in the Romanian Sector", Petre Roman, Emil Gruia, Simona Marcoci, Gheorghe Panaitescu, Research Report no. 213, ICPGA-IPB, 1975-1985.

[11] "We may be closer than we thought to Earth's dangerous tipping points", New Scientist Environment, 23 November 2019 and "Antarctica's Doomsday glacier is melting", New Scientist Environment, 15 January 2020.

[12] "Early atmospheric contamination on top of the Himalayas since the onset of the European Industrial Revolution", Paolo Gabrielli and others, Proceedings of the NAS of the USA, February 2020.

[13] Paul Heyne, "The Economic Way of Thinking", MacMillan Publishing Company, New York, 1987, pag. 233.

[14] Nicholas Georgescu - Roegen, "The Entropy Law and the Economic Process", Cambridge University Press, Mass, 1971, pp. 211-231.

[15] Nicholas Georgescu - Roegen, "The Entropy Law and the Economic Problem", Vanderbilt University, 1972, pp. 1-16.

[16] Thierry de Montbrial, "Thermodynamique et Économie", in "Sadi Carnot et l'essor de la thermodynamique", Editions du Centre National de la Recherche Scientifique, 1976, pp. 321338 . 